\title{
Thrombocytosis following thrombocytopenia in man
}

\author{
D. OGSTON \\ M.B., Ph.D. (Aberd.), M.R.C.P. (Lond. \& Ed.) \\ Lecturer in Medicine
}

\author{
Audrey A. DAWSON \\ M.D (Aberd.), M.R.C.P. (Ed.) \\ Senior Lecturer in Medicine
}

\section{University of Aberdeen}

\begin{abstract}
Summary
Observations are presented on the changes in the platelet count of patients during the treatment of Addisonian pernicious anaemia with vitamin $\mathbf{B}_{\mathbf{1 2}}$, of thrombocytopenic purpura with prednisone, and of malignant disease with methotrexate.

In each of these clinical situations, thrombocytopenia was succeeded, after a delay of a number of days, by a phase of thrombocytosis.
\end{abstract}

\section{Introduction}

An elevation in the circulating platelet count has been observed in a variety of physiological and pathological conditions. However, the rise in platelets varies widely in timing and duration. The myeloproliferative diseases are frequently accompanied by a persistent increase in the platelet count which may be of considerable magnitude. Such stresses as exercise are accompanied by a transient and moderate rise in platelets. In a number of circumstances, for example, trauma, the increase in platelets takes place after a delay of a number of days and lasts for a few days. We present observations on further examples of thrombocytosis of this last type occurring during the treatment of Addisonian pernicious anaemia with vitamin $\mathbf{B}_{12}$, of thrombocytopenic purpura with prednisone, and of cancer with methotrexate.

\section{Methods and patients}

\section{Platelet counts}

These were performed by the method of Oettle \& Spriggs (1951). The normal range for healthy adults in this laboratory is $150-270,000 / \mathrm{mm}^{3}$.

\section{Serum vitamin $B_{12}$ levels}

These were assayed microbiologically by the method of Spray (1955) using Lactobacillus leichmannii. The lower limit of normal for the laboratory is $160 \mathrm{pg} / \mathrm{ml}$.

Other haematological measurements were performed by the techniques described by Dacie \& Lewis (1963).

\section{Patients with Addisonian pernicious anaemia}

All fourteen patients had megaloblastic marrow smears, a histamine-fast achlorhydria, serum antiparietal cell antibodies, and a serum vitamin $\mathbf{B}_{12}$ of less than $160 \mathrm{pg} / \mathrm{ml}$. In some patients a Schilling test, with and without oral intrinsic factor, was performed to confirm the diagnosis of pernicious anaemia.

\section{Patients with thrombocytopenic purpura}

This group consisted of patients with thrombocytopenia which appeared to be the direct result of sensitivity to drugs, and of patients with idiopathic thrombocytopenia purpura using the diagnostic criteria given by Doan, Bouroncle \& Wisemano (1960) except that histological examination of the spleen was not possible.

\section{Results}

\section{Addisonian pernicious anaemia}

Fourteen patients with pernicious anaemia had platelet counts performed before and every 2 or 3 days after the start of therapy with intramuscular hydroxycobalamine. Eleven patients were thrombocytopenic before therapy, and nine of these had a rise in the platelet count to above normal levels after starting treatment; the peak platelet count was between 10 and 17 days after the first injection of vitamin $B_{12}$ (mean 14 days). No such platelet rise was demonstrated in patients starting with a normal platelet count (Table 1). The maximal platelet count occurred some days after the reticulocyte peak. Fig. 1 illustrates this difference in timing between the peak reticulocyte and platelet counts.

\section{Thrombocytopenic purpura}

Nine patients with acute thrombocytopenic purpura were studied. None required splenectomy and two recovered spontaneously. Seven were treated with a short course of prednisone. Six of the steroid-treated patients had a phase of thrombocytosis, the peak platelet count being 8-14 days after the start of prednisone (mean 10 days). The 
TABle 1. Platelet counts before and after start of vitamin $\mathbf{B}_{\mathbf{1 2}}$ therapy in patients with Addisonian pernicious anaemia

\begin{tabular}{rrrr}
\hline Patient & \multicolumn{2}{c}{ Platelet counts (per mm ${ }^{3}$ ) } & \multicolumn{2}{c}{\begin{tabular}{c} 
Time of highest \\
platelet count \\
\cline { 2 - 3 } therapy
\end{tabular}} & $\begin{array}{c}\text { Highest } \\
\text { count after } \\
\text { therapy }\end{array}$ & $\begin{array}{c}\text { after start } \\
\text { of therapy)* }\end{array}$ \\
\hline 1 & 46,000 & 331,000 & 16 \\
2 & 56,000 & 168,000 & - \\
3 & 23,000 & 385,000 & 17 \\
4 & 39,000 & 376,000 & 13 \\
5 & 46,000 & 321,000 & 14 \\
6 & 213,000 & 261,000 & - \\
7 & 185,000 & 248,000 & - \\
8 & 81,000 & 426,000 & 13 \\
9 & 18,000 & 298,000 & 16 \\
10 & 78,000 & 555,000 & - \\
11 & 10,000 & 230,000 & - \\
12 & 200,000 & 208,000 & 13 \\
13 & 115,000 & 564,000 & 12 \\
14 & 13,000 & 520,000 & \\
\hline
\end{tabular}

*Where in excess of normal platelet count.

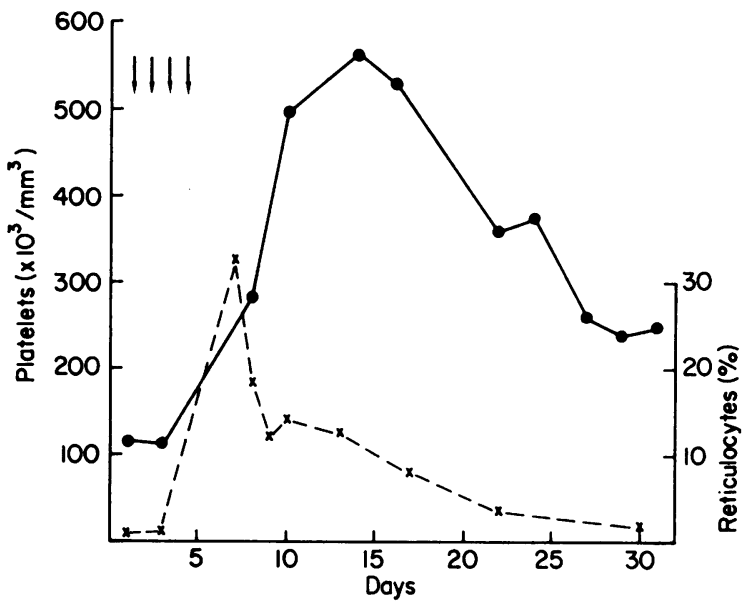

FIG. 1. Changes in the platelet $(O)$ and reticulocyte $(x)$ counts following the administration of vitamin $\mathbf{B}_{12}$ (arrows) to a patient with Addisonian pernicious anaemia.

platelet counts of three of these patients are illustrated in Fig. 2. The two patients who received no specific therapy had only a gradual rise in the platelet count without a phase of thrombocytosis. To exclude the possibility that prednisone may induce a thrombocytosis in normal subjects, $40 \mathrm{mg}$ of prednisone daily was taken by two healthy adults for 5 days. Their platelet counts before, during and after this course of prednisone are also illustrated in Fig. 2; no significant alterations in the platelet count took place.

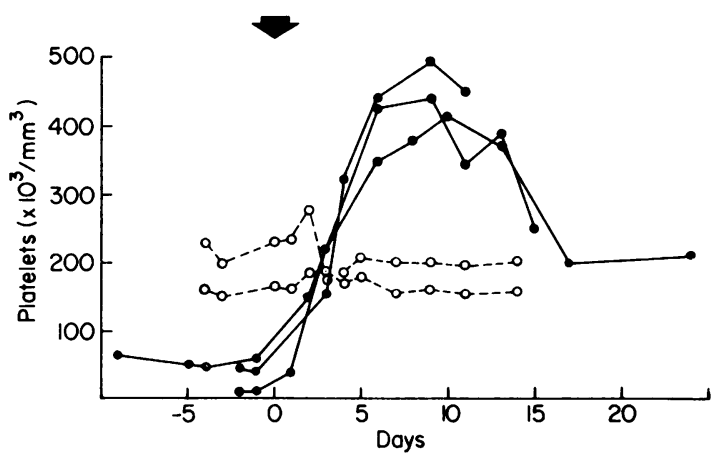

FIG. 2. Response of the platelet count to prednisone in three patients with thrombocytopenic purpura $(O)$ and in two normal subjects (O). Arrow indicates start of prednisone treatment.

\section{Methotrexate therapy}

We have repiorted previously that therapy with with methotrexate (amethopterin) is followed, in most patients, by a reduction in the platelet count, and that this period of thrombocytopenia is succeeded by a thrombocytosis, maximal 10-17 days after cessation of the drug (Ogston, Dawson \& Philip, 1968). This sequence of changes in the platelet count is illustrated in Fig. 3 from data obtained from three further patients given an intra-arterial infusion of methotrexate for the treatment of malignant disease. It can be seen that the peak platelet count occurred around 10 days after the time of the lowest platelet count.

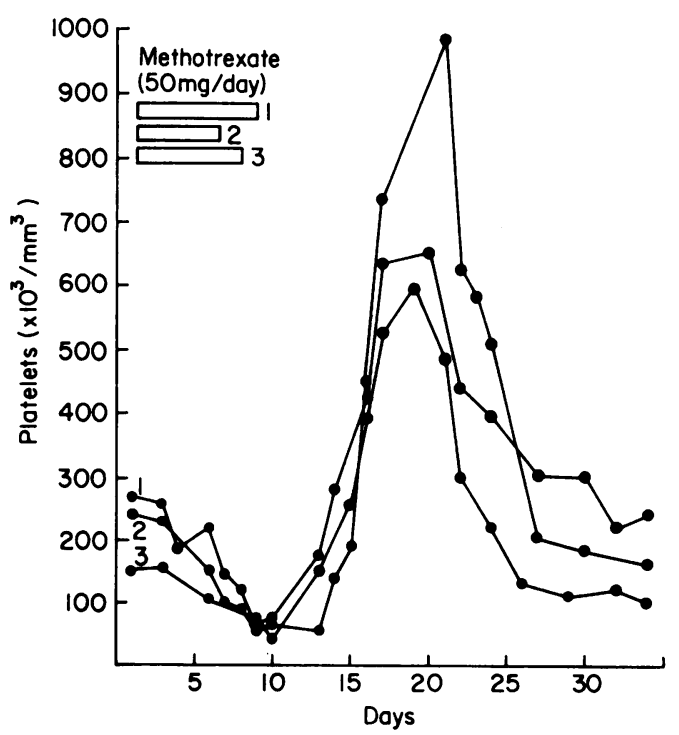

FIG. 3. Changes in the platelet count during and following the administration of intra-arterial methotrexate to three patients. 


\section{Discussion}

There is now considerable evidence from animal experiments that the level of circulating platelets influences their production by megakaryocytes. This evidence had been reviewed recently by Abildgaard \& Simone (1967) and by Ebbe (1968). It is widely believed that a feedback mechanism is mediated by a humoral factor termed 'thrombopoietin' which is released in response to thrombocytopenia (De Gabriele \& Penington, 1967a), and experimental thrombocytopenia in rats stimulates an increased production of platelets with a phase of thrombocytosis (Matter et al., 1960; Odell, McDonald \& Asano, 1962; De Gabriele \& Penington, 1967b).

The thrombocytopenia of untreated pernicious anaemia is well established (Paddock \& Smith, 1939), but we have been able to find only one previous study which draws attention to the moderate thrombocytosis occurring somie 2 weeks after the start of therapy with vitamin $\mathrm{B}_{12}$ (Rak et al., 1967). The thrombocytopenia secondary to vitamin $B_{12}$ deficiency and to methotrexate therapy presumably results from interference with normal megakaryocyte metabolism.

Most investigators consider that the deficiency of platelets in idiopathic thrombocytopenic purpura results from accelerated destruction of platelets by antibodies rather than from a primary deficit in production (Davey, 1966; Najean et al., 1967). Thrombocytopenia due to drug sensitivity is probably also secondary to antibody formation. In both types of thrombocytopenia the rationale of prednisone therapy is to diminish the damaging effect of antigen-antibody reactions at the surface of platelets.

We have illustrated three situations in man where thrombocytopenia, produced by different mechanisms, is commonly succeeded by thrombocytosis some 10-14 days after the elimination of factors depressing platelet production or destroying formed platelets. These clinical observations favour the view, therefore, that thrombocytopenia in man, as in experimental animals, induces the release of a substance which stimulates platelet production.

\section{References}

AbildgaARd, C.F. \& Simone, J.V. (1967) Thrombopoiesis. Semin. Hemat. 4, 424.

Dacie, J.V. \& Lewis, S.M. (1963) Practical Haematology, 3rd edn. Churchill, London.

Davey, M.G. (1966) The Survival and Destruction of Human Platelets. Karger, Basel.

De Gabriele, G. \& Penington, D.G. (1967a) Regulation of platelet destruction: 'thrombopoietin'. Brit. J. Haemat. 13, 210.

De Gabriele, G. \& Penington, D.G. (1967b). Physiology of the regulation of platelet production. Brit. J. Haemat. 13, 202.

Doan, C.A., Bouroncle, B.A. \& Wiseman, B.K. (1960) Idiopathic and secondary thrombocytopenic purpura: Clinical study and evaluation of 381 cases over a period of 28 years. Ann. intern. Med. 53, 861 .

EввE, S. (1968) Megakaryocytopoiesis and platelet turnover. Ser. Haemat. 1, 65.

Matter, M., Hartmann, J.R., Kautz, J., De Marsh, Q.B. \& FinCH, C.A. (1960) A study of thrombopoiesis in induced acute thrombocytopenia. Blood, 15, 174.

Najean, Y., Ardaillou, N., Dresch, C. \& Bernard, J. (1967) The platelet destruction site in thrombocytopenic purpuras. Brit. J. Haemat. 13, 409.

Odell, T.T., JR, McDonald, T.P. \& Asano, M. (1962t Response of rat megakaryocytes and platelets to bleeding Acta haemat. (Basel), 27, 171.

Oettle, A.G. \& Spriggs, A.I. (1951) New optial and cyto? chemical techniques in haematology. Recent Advances in Clinical Pathology, 2nd edn, p. 406, Churchill, London.

Ogston, D., Dawson, A.A. \& Philip, J.F. (1968) Methotrexate and the platelet count. Brit. J. Cancer, 22, 244.

PadDock, F.K. \& Smith, K.E. (1939) Platelets in pernicious anaemia. Amer. J. med. Sci. 198, 372.

Rák, K., Krizsa, F., Varga, L. \& Cserháti, I. (1965) Untersuchung der Thrombocytopoese bei PerniciosaKranken. Acta haemat. (Basel), 34, 175.

SPRAY, G.H. (1955) An improved method for the rapid estimation of vitamin $B_{12}$ in serum. Clin. Sci. 14, 661 . 